\title{
The Effect of Discourse Analysis Informed Instruction on Developing High School Learners Reading Comprehension
}

\author{
Hawa Mohammed \\ Department of English Language and Literature, Woldia University, Woldia, Ethiopia \\ Email address: \\ Hawamohammed99.hm@gmail.com \\ To cite this article: \\ Hawa Mohammed. The Effect of Discourse Analysis Informed Instruction on Developing High School Learners Reading Comprehension. \\ International Journal of Secondary Education. Vol. 8, No. 2, 2020, pp. 20-26. doi: 10.11648/j.ijsedu.20200802.11
}

Received: September 24, 2019; Accepted: November 5, 2019; Published: May 18, 2020

\begin{abstract}
This study scrutinized the effect of discourse analysis (DA) informed instruction on developing high school English as a foreign language (EFL) learners reading comprehension. A quantitative research method with quasi-experimental pre-test post-test comparison group design was utilized for the study. The participants were two intact sections of $10^{\text {th }}$ graders $(\mathrm{n}=88)$ that were selected purposively based on pre-test mean scores from Woldia Millennium General Secondary School in North Wollo, Ethiopia. The data were collected through reading comprehension test: pre-test and post-test. T-tests including independent samples test and paired samples test were employed in data analysis as statistical tools. The result ( $\mathrm{t}(91)-.025$, $\mathrm{p}>$.980) reveals that both the experimental and the control groups were almost equal in reading comprehension achievement before the experiment. However, after the treatment, the analysis of data ( $\mathrm{t}(86) 3.923, \mathrm{p}<0.001)$ with effect size 0.82 indicates that the experimental group significantly outperformed the control group on reading comprehension post-test with the primacy of DA informed instruction over the usual method. Therefore, the findings of the study advocates that DA informed reading instruction significantly boost up high school students' reading skill, and it is recommended to be used
\end{abstract}

Keywords: Discourse Analysis, Cohesion, Cohesive Devices, Reading Comprehension, General Secondary School, EFL Learners

\section{Background of the Study}

As a receptive language skill, reading is a major means of communication which determines the amount of information students receive in a certain text because reading requires understanding of a text as a whole called reading comprehension. Reading comprehension is neither just a single incident nor develops naturally rather it builds up gradually as a reader becomes more fluent, skillful and confident [1]. In other words, the ability to understand texts requires learners' reading competence that is accumulated through time with continuous reading practice.

However, most EFL learners at Woldia Millennium General Secondary School hardly comprehend reading passages. Students have always complained that reading comprehension is a difficult task, and they have desperately worried about the reading comprehension questions which they would face in final examinations and matriculation. Evidence also shows that high school

EFL students' reading comprehension is ineffective [2, 3, 4,
5, 6, and 7]. There may be different contributing factors, but some researchers recommend that lack of students understanding of techniques on DA [5] and the absence of discourse based instruction [7] were among them. However, DA has not been considered so far in the local context while it has been found as one important factor for students' limited comprehension.

DA is a social constructivism approach and a research method of linguistics which primarily examines the use of language along with its function and form [8]. It concerns about how stretches of language is used in utterance which presuppose meaning, purpose and unity for the users [9]. The knowledge of discourse specifically cohesion and coherence is used in DA to describe the properties of written texts since both are crucial elements of a text to make the progress of reading comprehension smooth and easy by creating textual continuity (Halliday and Hasan, 1976) [10]. they state that cohesion refers to the ties that join a text together on the surface structure and can be revealed in a text through the use of cohesive devices including reference, substitution, ellipsis 
and conjunction as grammatical cohesion, and reiteration (i.e. repetition, synonym, antonym, general noun and hyponym) and collocation as lexical cohesion. Coherence, on the other hand, is the conceptual relationship between sentences; it is the connection between utterances or propositions through discourse structure, meaning, and action being combined [11 and 12]. It allows readers to move easily thorough the text as a whole by creating meaningful ideas in the reader's mind. Thus, it is possible to say that learners' knowledge on cohesive devices makes them conscious on signals of relations that illustrate how a text should be understood; their various functions also help readers to integrate the several different parts of a text which is fundamental for the production of discourse, and consequently help to create coherence.

This implies that there is a rapport between discourse (i.e. coherence and cohesion) and reading comprehension as discourse patterns provide clues in a written text. Besides, reading comprehension requires the ability to recognize discourse level relationships which is used to build and support comprehension [13]. Sanders and Maat (2006) [14] also signify the link between vocabulary and lexical cohesion because of the fact that lexical cohesion is captured by the choice of vocabulary which is a basic sub-skill needed to understand reading texts. Generally, Students knowledge on cohesive devices basis their reading comprehension by enabling them understand and grasp the various meanings and textual connotations a text has and by helping them to make out whether a piece of writing is semantically, grammatically and lexically correct. Evidence also shows that linguistic knowledge of learners, specifically discourse level knowledge including text organization and cohesion significantly affects individuals' reading comprehension [15].

Overall, this relation between cohesive ties and reading comprehension, the absence of discourse based instruction in teaching reading as well as learners' limited comprehension were formed the backdrop to conduct the present study.

\section{Statement of the Problem}

English in Ethiopia has a foreign language status. It is taught as a subject starting from grade one and used as a medium of instruction particularly from secondary school on wards; that is why all the academic materials are prepared in English language. Besides, English as international language, a large extent of literature are published in English these days Thus, to understand these materials, reading is by far the most fundamental skill that EFL learners should maintain and develop earlier in their education. Further, learners' academic success or failure highly depends on their ability to read and understand texts of different subjects. To this end, Atkins, Hailom and Nuru (1996: 39) [16] inform that "...eventual academic success or failure depends on a large degree on students' ability to read and comprehend textbooks and notes they receive in different subjects they study." Thus, learners need to have good reading ability to promote their studies successfully and to facilitate their communication.
However, EFL learners in Ethiopian context encounter problems on understanding texts. From experiential knowledge, it has been realized that even if high school students have been taught English for about nine or ten years, they often end in failure in reading comprehension. Besides, many EFL teachers have complained that most of their students were poor readers, [2, 3, 4, 5, 6, 17 and 7]. Not only teachers but also parents and students themselves reported that high school students' reading comprehension difficulty is a considerable problem [6]. Thus, there needs to develop learners reading comprehension through the application of DA informed instruction in reading lessons.

As researchers found out, among the factors that affect EFL learners' reading comprehension are: lack of understanding of techniques on DA [5] and the absence of discourse based instruction [7]. These cause students to perform poorly in reading activities such as identifying discourse structures and recognizing their meanings and functions when they read texts. In this regard, Samual (2011) [6] finds out that students have limited knowledge of vocabulary and grammar; consequently, they are less likely to practice reading activities such as recognizing implied ideas and consolidating texts; knowledge of vocabulary includes the students' ability to understand words and conceptualize their relations such as repetition, synonym, antonym, hyponym, collocation etc in reading activities. Thus, scarcity of knowledge on these aspects of vocabulary directs students to limited ability to comprehend reading passages.

Even if local researchers studied on students' reading comprehension in different titles such as factors affecting reading comprehension [5, 6 and 17], the practice of teaching reading [18], extensive reading: perception and practice [19], secondary school students reading strategy use [20], status and determinants to reading skill development [7], explicit reading strategy [21], no one has tried to examine the effect of DA on reading comprehension development. Thus, as far as my reading is concerned, the area hasn't been researched yet on the present title, and it is found vital to help students in identifying different types of cohesive relations in texts during reading lessons

In fact, some foreign researchers realize that discourse based approach in teaching reading helps learners for better reading comprehension (Wenquan, 2009 [22]; Ivanovo 2009 [23]; Aidonlou et. al 2012 [24] and Sabet et al, 2013) [25]. They found out DA in reading classroom facilitate language learning in general and reading comprehension in particular and conclude that language teaching is almost unfeasible without adopting a discourse-oriented approach. However, these studies are conducted in foreign context and mostly at advanced level so the results are inconclusive. Conversely, the present study considered the problem by taking into account DA informed instruction as an approach to build up EFL learners reading comprehension as empirical study in local context.

\section{Research Questions}

To achieve its purpose, this study tries to answer the 
following research question:

Does DA informed instruction for teaching reading significantly improve reading comprehension of EFL learners at Woldia Millennium General Secondary School?

This question was divided into the following four subquestions:

i. Is there a significant difference between the pre-test mean scores of students in the experimental and the controlled group?

ii. Is there a significant difference between the post-test mean scores of students in the experimental and the controlled group?

iii. Is there a significant difference between the pre-test and post-test mean scores of students in the experimental group?

iv. Is there a significant difference between the pre-test and post-test mean scores of students in the controlled group?

\section{Significance of the Study}

First and foremost, this study may recommend syllabus designers and text book producers to consider possible circumstances for cohesive devices when they prepare reading comprehension activities for high school EFL learners. Next, the findings of this study may possibly initiate EFL teachers to see back to their trend of teaching reading skill and appraise their students reading performance to make adjustment on the ways of teaching reading skills into the direction that helps learners to get new insights and input through DA informed reading instruction. Finally, this study may serve as a stepping stone for further research since there is no study conducted in the area in Ethiopian general secondary school context.

\section{Scope of the Study}

This study is delimited to Woldia Millennium General Secondary School, which is a government school found in North Wollo Zone, in the Amhara National Regional State. Specifically, the study was limited to two out of ten sections of Grade $10^{\text {th }}$ students enrolled in 2016/2017 academic year; they were selected using purposive sampling. Besides, the study was delimited to two applications of discourse analysis: cohesion and coherence because cohesive devices are closely linked with texts, so they are easily accessible. Likewise, reading skill is selected over other skills because of the reality that reading determines not only students' English proficiency but also their understanding of different subjects since all academic materials require students ability to read and grasp ideas.

\section{Research Design}

This study has followed a quantitative research method with quasi-experimental pre-test post-test comparison group design in which one group received discourse analysis informed reading instruction in reading lessons as a treatment while the other representing the same population as the experimental subjects, did not. The design was pertinent to manipulate discourse analysis informed reading instruction to see its effect on students reading comprehension development.

\subsection{Participants}

Two sections which were $10^{\text {th }} \mathrm{A}(\mathrm{N}=43)$ as a comparison group and $10^{\text {th }} \mathrm{F}(\mathrm{N}=45)$ as an experimental group were taken as samples of the study from ten grade ten sections of Woldia Millennium General Secondary School enrolled in 2016/2017. The subjects were selected based on results of the pre-test which was given for the ten sections, and two sections having closer mean scores were taken as samples. Therefore, they were purposively selected based on their score proximity. However, $10^{\text {th }} \mathrm{A}$ as a controlled group and $10^{\text {th }} \mathrm{F}$ as an experimental group were identified randomly using a lottery system.

\subsection{Data Collection Instrument}

Pre and post tests were used as the main instruments for the data needed for the study to achieve its objectives and to obtain possible answers for the research question. They are valuable instruments for comparing performance of subjects prior to a certain treatment with performance of subsequent treatment [26]. The same reading comprehension test which was adapted from grade 10th English for Ethiopia Student's textbook was designed not only for the subjects but also for the population as a pre-test. The purpose was to recognize their reading comprehension achievement before the treatment; then, to identify two sections having closer mean scores to assign in the experimental and controlled groups. Moreover, the post-test was used to examine the effect of DA informed instruction on learners reading comprehension development. Kuder Richardson 20 method of calculating reliability was employed to measure the internal consistency of the items and it was found 0.86 alpha level which was good reliability

\subsection{Data Analysis}

The data gathered through the pre and post-tests were analyzed through paired sample $t$-test and independent sample $t$ - test. Paired sample t-test was used to make a paired comparison between pre and post-test scores obtained from each group. Independent samples t-test was used to make comparisons between the two groups means. To determine significant differences in or between the groups an alpha level of .05 and a two-tailed test were used. The data were analyzed using SPSS version 21 software. However, Test of normality was measured using One-Sample KolmogorovSmirnov Test before t-tests were computed and the result indicates that $\mathrm{D}(45)=1.004, \mathrm{p}>.05$ for the experimental and $\mathrm{D}(46)=1.125, \mathrm{p}>.05$ for the controlled group which means the samples distribution almost fit the assumption of normality. 


\section{Results}

\subsection{Analysis Related to Research Question One}

To find out if there is a significant difference between the pre-test mean scores of students in the experimental and controlled group, an independent sample $\mathrm{t}$ - test was computed as shown below.

Table 1. Descriptive statistics of the experimental and the controlled groups pre-test scores (N=93).

\begin{tabular}{llllllll}
\hline Pre-test & N & Range & Min & Max & Mean & Standard Error & Std. Deviation \\
\hline Experimental Group & 46 & 12 & 2 & 14 & 7.26 & .423 & 2.871 \\
Controlled Group & 47 & 12 & 2 & 14 & 7.28 & .459 & 3.146 \\
Valid N (listwise) & 46 & & & & & & \\
\hline
\end{tabular}

As the table indicates, the mean scores of the experimental and the controlled groups are 7.26 and 7.28 respectively. The standard deviation of the pre-test score was 2.871 for the experimental and 3.146 for the controlled group students, but the maximum and the minimum score for both groups are the same.

Table 2. Independent Samples Test for equality of means for the experimental and controlled group's pre-test score.

\begin{tabular}{|c|c|c|c|c|c|c|c|c|}
\hline $\begin{array}{l}\text { Levene's Test } \\
\text { Equality of V }\end{array}$ & $\begin{array}{l}\text { or } \\
\text { riances }\end{array}$ & t-test $f$ & Equality & Ieans & & & & \\
\hline \multirow[t]{2}{*}{$\mathbf{F}$} & \multirow[t]{2}{*}{ Sig. } & \multirow[t]{2}{*}{$\mathbf{t}$} & \multirow[t]{2}{*}{ df } & \multirow[t]{2}{*}{ Sig. (2-tailed) } & \multirow{2}{*}{$\begin{array}{l}\text { Mean } \\
\text { Difference }\end{array}$} & \multirow{2}{*}{$\begin{array}{l}\text { Std. error } \\
\text { Difference }\end{array}$} & \multicolumn{2}{|c|}{$\begin{array}{l}95 \% \text { Confidence Interval of } \\
\text { the Difference }\end{array}$} \\
\hline & & & & & & & Lower & Upper \\
\hline Equal variance assumed .923 & .3 & -.025 & 91 & .980 & -.016 & .625 & -1.257 & 1.226 \\
\hline Equal variance not assumed & & -.025 & 90.559 & .980 & -.016 & .624 & -1.256 & 1.225 \\
\hline
\end{tabular}

Table 2 revels $(t$ (91) $-.025, p>.980$ which means the $\mathrm{P}$ value is greater than 0.05 alpha level, so there is no significant statistical difference between the subjects of the experimental and the controlled groups in the entry performance. Thus, the two groups have similar reading comprehension performance. The effect size for this comparison is 0.006 which is weak effect.

\subsection{Analysis Related to Research Question Two}

An independent sample $\mathrm{t}$ - test was also computed to test whether there is a significance difference between the posttest mean scores of students in the experimental and the controlled groups.

Table 3. Descriptive statistics of the experimental and the controlled groups post-test scores $(N=88)$.

\begin{tabular}{llllllll}
\hline Students & N & Range & Min & Max & Mean & Std. Deviation & Std. Error Mean \\
\hline Experimental Group & 45 & 14 & 2 & 16 & 9.96 & 3.542 \\
Control Group & 43 & 12 & 3 & 15 & 7.30 & 2.730 & .528 \\
\hline
\end{tabular}

Table 3 portrays that the mean score of the experimental group is 9.96 while the mean score of the controlled group is 7.30 which is less than the experimental group students' score. The standard deviation is 3.542 for the experimental and 2.730 for the controlled group. This proves that there is a difference between the mean scores of the experimental and the controlled group in the post-test scores

It is worth mentioning that in the descriptive statistics table
1 above the number of samples in the pre-test were 46 for the experimental and 47 for the controlled group, but in table 3 the samples become 45 for experimental and 43 for controlled group i.e., 1 student from the experimental and 4 students from the controlled group didn't take the post-test. Therefore, these five students were excluded in the post-test and the samples became 88 .

Table 4. Independent samples test for equality of means for the experimental and controlled groups' post-test score.

\begin{tabular}{|c|c|c|c|c|c|c|c|c|}
\hline \multicolumn{2}{|c|}{$\begin{array}{l}\text { Levene's Test for } \\
\text { Equality of Variances }\end{array}$} & \multicolumn{7}{|c|}{ t-test for Equality of Means } \\
\hline \multirow[t]{2}{*}{$\mathbf{F}$} & \multirow[t]{2}{*}{ Sig. } & \multirow[t]{2}{*}{$\mathbf{t}$} & \multirow[t]{2}{*}{ df } & \multirow{2}{*}{$\begin{array}{l}\text { Sig. (2- } \\
\text { tailed) }\end{array}$} & \multirow{2}{*}{$\begin{array}{l}\text { Mean } \\
\text { Difference }\end{array}$} & \multirow{2}{*}{$\begin{array}{l}\text { Std. error } \\
\text { Difference }\end{array}$} & \multicolumn{2}{|c|}{$\begin{array}{l}\text { 95\% Confidence Interval of } \\
\text { the Difference }\end{array}$} \\
\hline & & & & & & & Lower & Upper \\
\hline Equal variance assumed .281 & .598 & 3.923 & 86 & .000 & 2.770 & .722 & 1.335 & 4.204 \\
\hline Equal variance not assumed & & 3.856 & 85.764 & .000 & 2.770 & .720 & 1.338 & 4.201 \\
\hline
\end{tabular}

Table 4 reflects the mean score difference of the experimental and the controlled group on reading comprehension post-test sore. The result ( $t$ (86) 3.923, $\mathrm{p}<0.001)$ reveals that there is a statistical significant difference between the experimental and the controlled group, favoring the experimental group participants. Therefore, it can be noted that the experimental group performed significantly better than the controlled group in the post-test after receiving instruction in DA. The effect size for the posttest is 0.82 which shows that the magnitude of the treatment is moderate. 


\subsection{Analysis Related to Research Question Three}

A paired sample $t$ - test was computed to verify if there is a significant difference between the pre-test and post-test mean scores of students in the experimental group.

Table 5. Descriptive Statistics of the experimental group students' pre and post-test scores.

\begin{tabular}{llllllll}
\hline Test Scores & N & Range & Min & Max & Mean & Std. Deviation & Std. Error Mean \\
\hline Pre-test Score & 46 & 12 & 2 & 14 & 7.26 & 2.871 & .306 \\
Post-test Score & 45 & 14 & 2 & 16 & 9.96 & 3.542 & .449 \\
\hline
\end{tabular}

As table 5 displays, the mean scores of the experimental group pre and post reading comprehension tests are 7.26 and 9.96 respectively. It reveals a higher result in the post-test when comparing it with the pre-test score. Thus, the experimental group's pre and post reading comprehension mean scores are different.

Table 6. Paired Samples test for equality of means of the experimental group students pre and post-test scores.

\begin{tabular}{|c|c|c|c|c|c|c|c|c|}
\hline \multirow[t]{2}{*}{ Test Scores } & \multirow[t]{2}{*}{ Mean } & \multirow[t]{2}{*}{ Std. Deviation } & \multirow[t]{2}{*}{ Std. Error Mean } & \multicolumn{2}{|c|}{$\begin{array}{l}95 \% \text { Confidence Interval } \\
\text { of the Difference }\end{array}$} & \multirow[t]{2}{*}{$\mathbf{t}$} & \multirow[t]{2}{*}{ df } & \multirow[t]{2}{*}{ Sig. (2-tailed) } \\
\hline & & & & Lower & Upper & & & \\
\hline Pre-test - Post-test Score & -2.644 & 2.533 & .378 & -3.405 & -1.883 & -7.003 & 44 & .000 \\
\hline
\end{tabular}

The table shows ( $\mathrm{t}(44)-7.003, \mathrm{P}<0.001)$ which indicates a comparison of the means scores obtained by the experimental group subjects in the pre-and post-tests has a significant difference favoring post-testing. The effect size is also 0.8 which is moderate. The two tests were correlated at $(\mathrm{r}=0.7)$ which is significant at 0.001 alpha level.

\subsection{Analysis Related to Research Question Four}

A paired sample $t$ - test was again computed to see if there is a significant difference between the pre-test and post-test mean scores of students in the control group. Tables 7 and 8 below indicate the results.

Table 7. Descriptive Statistics of the controlled group students pre and post-test scores.

\begin{tabular}{|c|c|c|c|c|c|c|c|}
\hline & $\mathbf{N}$ & Range & Min & Max & Mean & Standard Error & Std. Deviation \\
\hline Pre-test & 47 & 12 & 2 & 14 & 7.28 & .459 & 3.146 \\
\hline Post-test & 43 & 12 & 3 & 15 & 7.30 & .489 & 3.209 \\
\hline Valid N (listwise) & 43 & & & & & & \\
\hline
\end{tabular}

As can be seen in the table, the controlled group pre-test mean score is 7.28 where as the post-test mean score is 7.30 . This shows that there is a difference between the pre and post reading comprehension performance of subjects favoring post testing.

Table 8. Paired Samples test for equality of means of the controlled group students pre and post-test scores.

\begin{tabular}{|c|c|c|c|c|c|c|c|c|}
\hline \multirow[t]{2}{*}{ Test Scores } & \multirow[t]{2}{*}{ Mean } & \multirow[t]{2}{*}{ Std. Deviation } & \multirow[t]{2}{*}{ Std. Error Mean } & \multicolumn{2}{|c|}{$\begin{array}{l}95 \% \text { Confidence Interval of } \\
\text { the Difference }\end{array}$} & \multirow[t]{2}{*}{$\mathbf{t}$} & \multirow[t]{2}{*}{ df } & \multirow[t]{2}{*}{ Sig. (2-tailed) } \\
\hline & & & & Lower & Upper & & & \\
\hline Pre-test - Post-test Score & .023 & 2.435 & .371 & -.726 & .773 & -.058 & 42 & .954 \\
\hline
\end{tabular}

Table 8 depicts a comparison of the mean scores obtained by the controlled group subjects in the reading comprehension pre-post-tests. The table reveals ( $\mathrm{t}(42)-.058$, p.>.954) which indicates there is no significant difference between the mean scores of the pre and post reading comprehension scores of the controlled group subjects. The result, thus, shows that the controlled group students have not shown significant difference in their reading comprehension performance in the post-test. The effect size is 0.02 which is weak.

\section{Interpretation and Discussion of Findings}

Comparison of pre-test scores of both the experimental and controlled groups indicated that there was no significant difference between the two groups and both groups were almost equal in their reading comprehension performance. This implies that the subjects in both groups had the same background in their levels of reading comprehension before the treatment was going on, so they were homogeneous. This consideration made possible the groups could be taken as experimental and controlled groups.

The experimental group, however, performed significantly better than the controlled group in the post-test; as shown in Table 4, the difference between the post-test mean scores of the two groups was significant at $\mathrm{P}<0.01$, The measurement effect 0.82 also confirms that the relative strength of the treatment was large. Thus, the research question which is "is there a significant difference between the post-test mean scores of students in the experimental and the controlled group?" was answered yes in favor of the experimental group participants. This grounds to answer the research question "does DA informed instruction for teaching reading 
significantly improve reading comprehension of EFL learners at Woldia Millennium General Secondary School?" yes. The correlation between the pre and post-tests was significant at $\mathrm{p}$-value $<0.01$ with Pearson correlation test statistics $(\mathrm{r}=0.65)$ which showed that the two tests had moderate relationship.

Correspondingly, the experimental group students performed better in the post-test than the pre-test. As the paired difference statistics denotes in table 6 , the pre-post paired mean score difference of the experimental group students was ( $\mathrm{t}(44)-7.003, \mathrm{P}<0.001)$. This means, the difference was significant and the effect size 0.8 implies that the magnitude of the treatment in the experimental group post test score was true and large. Thus, it confirms to answer the research question "is there a significant difference between the pre-test and the post-test mean scores of students in the experimental group?" yes, favoring the post-test.

On the contrary, the paired difference statistics ( $\mathrm{t}$ (42) $.058, \mathrm{p}>.954)$ in table 8 specifies that the controlled group participants pre-post paired mean score difference was not significant at 0.05 alpha level with weak effect size which is 0.02 . As a result, the research question "is there a significant difference between the pre-test and post-test mean scores of students in the control group?" proved no.

Overall, students who participated in the experiment demonstrated greater results in reading comprehension achievement as measured in the post-test when comparing it with the pre-test result that the students had initially. Therefore, the potential grounds to account for the significant result in the experimental group reading comprehension test could be the implementation of DA informed reading instruction during the reading sessions.

The result of the present study reassures the findings of previous studies conducted at foreign settings. For instance, it supports result of Wanquan (2009) [22] which showed that discourse-based approach has good effects on students' reading comprehension, but it was conducted at University level via the Internet through Google based on Macro and micro level as well as overall comprehension of discourse. The finding of the present study is also consistent with the results of Aidonlou. et. al (2012) [24] and Sabet et al (2013) [25] conducted on Iranian EFL learners. The former found out that the use of textual cohesive instruction in the reading classroom within the framework of cohesive structures is a fruitful tool in facilitating reading comprehension. However, it was conducted at university level and focused on only reference. The later found out that discourse based instruction was effective and cohesive ties affected EFL learner's reading comprehension and had a positive effect on students' reading comprehension, but it excluded discourse markers as cohesive device, and it was conducted at college level.

On the top of these, the result of the present study coincides with the findings of Raid (2011) [27] and Naziri and Rajeski (2014) [28] conducted at high school levels. Raid (2011) examined the impact of vocabulary and cohesive devices knowledge, especially pronouns and conjunctions on $11^{\text {th }}$ graders of Iranian EFL learners and found out that vocabulary, pronoun and conjunction predict and positively affected reading comprehension of students, but he didn't consider cohesive devices such as substitution, ellipsis, reiteration and collocation even other references such as demonstrative and comparative references. Besides, Naziri and Rajeski (2014) [28] found out that teaching cohesive devices explicitly proved to have a significant impact on improving learners reading comprehension skills in EFL classrooms. Even if they considered both grammatical and lexical cohesive devices in their study, nothing indicates the grade level and the sampling technique was convenience.

\section{Conclusions}

The experimental group students' post-test reading comprehension achievement significantly exceeds that of the controlled group. On the basis of this finding, it can be concluded that the effects of DA informed reading instruction is better than that of the usual method of reading instruction because this new approach helps to improve the students' reading comprehension achievement by engaging them in the identification and analysis of cohesive element, so it increases the students' understanding of what they read.

Second, a significant difference in the experimental group students reading comprehension achievement was observed after the implementation of DA informed reading instruction. In other words, the experimental group students demonstrated a better achievement in the reading comprehension post-test than in the pre-test. This result confirms that DA informed reading instruction boosts more significant effect on the experimental group participants.

Finally, the finding of the study implies that high school students might not show a better reading comprehension performance if they continue to learn in the usual method. Thus, it is possible to conclude that DA informed reading instruction is useful for improving reading comprehension of students.

\section{Recommendations}

\subsection{Recommendations for Practice}

Based on the findings of the study, it is recommended that there needs to have room to implement DA informed instruction for teaching reading in high school EFL classrooms, but it is better to be used after the result of this study would have been validated in other school. Besides, the result of this study leads to infer that training teachers for using DA informed reading instruction is crucial and appropriate to enable them engage the students in the learning process. Therefore, in service training should be provided for EFL teachers on techniques of DA in general and cohesive elements in particular. Hence, stakeholders may aware of it to take the responsibility for providing possible opportunities for EFL teachers to get the access to training. Finally, the findings of this study may recommend syllabus designers and textbook producers to consider cohesive devices when they design reading comprehension activities. 


\subsection{Recommendations for Further Study}

As the sample of the study might not represent high school students in general, the study should be replicated with other similar samples, so future research on more participants in more school classes using similar procedures could be advisable. On the other hand, apart from the quantitative method, DA may be examined in EFL classroom related to classroom discourse through a qualitative approach. Therefore, it is worthwhile to conclude by noting the need for additional research to fill the gap, to validate, and provide new insights into effective reading instruction.

\section{References}

[1] Harrison, C. (2004). Understanding how we learn from texts. New Delhi. Sega publication.

[2] Mendida Berkessa. (1988). A comparison of the reading level of Bahir Dar teachers' college freshman students with the reading level expected of them. Unpublished Thesis) Addis Ababa University: Ethiopia.

[3] Genene Mekonnen. (1994). A comparison of the reading abilities of junior secondary school students with the reading levels required of them in the content areas. (UnpublishedThesis). Addis Ababa University: Ethiopia.

[4] Andargachew Moges. (2004) Reader self-efficacy and reading achievement of Region 6 college preparatory students: Grade 11 in focus (unpublished thesis) Addis Ababa University. Ethiopia.

[5] Edaso Mulu. (2007). An exploration of factors affecting preparatory school students Reading comprehension skill (Unpublished thesis). Addis Ababa University. Ethiopia.

[6] Samual Moges. (2011). Factors that affect Students' Reading Comprehension in to government high schools: Grade 9 students in focus (unpublished thesis). Addis Ababa University. Ethiopia.

[7] Solomon Abera. (2014). Status and determinants to reading skill development: (Unpublished thesis). Addis Ababa University, Ethiopia.

[8] McCarthy, M. (1991). Discourse analysis for language teachers: UK. CUP.

[9] Jhonson, K and Jhonson, H. (1999). Encyclopedic dictionary of applied linguistics. USA. Blackwellpublisher.

[10] Halliday, M. \& Hasan R. (1976). Cohesion in English. London: Longman.

[11] Dijk, V \& Kintsch, W. (1983). Strategies of discourse comprehension. New York: Academic press.

[12] Schiffrin, D. (2001). Discourse markers: language, meaning, and context. In Schiffrin, D. Tannen, D. and. Hamilton, H. (E. ds.). The Handbook of Discourse Analysis (pp 55-75). USA. Blackwell.
[13] Grabe, W. (2009). Reading in second language: Motivating from theory to practice. Cambridge CUP.

[14] Sanders, T. and Maat, H. P. (2006). Cohesion and coherence; Linguistics' approaches: Netherland. Utrecht University.

[15] Alderson, J. C. (2000). Assessing reading: United Kingdom. CUP.

[16] Atkins, J., Hailom Banteyerga and Nuru Mohammed. (1996). Skills development methodology Part 2. Addis Ababa University: Ethiopia.

[17] Tsegaye Desta. (2013). Assessing the factors that challenge the reading habits of Second Year English Department Students in Hosanna College. (Unpublished thesis). Haromaya University. Ethiopia.

[18] Mesfin Derash. (2008). The practice of teaching reading in English at first cycle primary schools (Unpublished thesis). Addis Ababa University. Ethiopia.

[19] Abinet Mengiste. (2011) Extensive reading: Perception and practi (Unpublished thesis). Addis Ababa University. Ethiopia.

[20] Yohans Tefera. (2013). A survey of secondary school students' reading strategy use, teachers' perceptions and practices: (Unpublished Thesis) Ethiop. J. \&Sc. Vol. 8. No. 2.

[21] Dawit Tibebu. (2014) The Effect of Explicit Reading Strategy Instruction on Reading Comprehension of Upper Primary Grade students. International Journal of Education Vol. 6, No. 3.

[22] Wenquan, W. 2009. Application of discourse analysis in college reading class. Retrieved from http:www.scribd.com/40905618/.

[23] Ivanov, S. (2009). Discourse analysis in EFL reading. Retrived from http// www. Dspace.mah. se/bitstream/handle/2043.

[24] Aidinlou, N. Khodamard, N. and Azami, J. (2012). The effect of textual cohesive reference instruction on the reading comprehension of Iranian EFL students: International Journal of English Linguistics Vol. 2, No. 5.

[25] Sabet, A., Khodabandehlou, M. and Jahandar, S. (2013). The impact of instructing discourse markers on Iranian EFL learner's reading comprehension ability. Indian Journal of Fundamental and Applied Life Sciences. Vol. 3 (3), pp. 273280 Retrieved http://www.cibtech.org/jls.htm.

[26] Mackey, A\& Gass, S. (2005) Second Language Research, Methodology and Design London. Lawrence Erlbaum Associate. Inc.

[27] Raid Al. Farra. (2011) The impact of lexical and cohesive devices knowledge on $11^{\text {th }}$ graders reading published thesis) Islamic University of Gaza Retrieved from http://www.academia.edu/.

[28] Naziri, M and Rajeski, J (2014). Cohesive Device Frequency in English Textbooks: Do They Help or Hinder EFL Reading Comprehension? International Journal of Applied Linguistics \& English Literature Vol. 3 No. 4; doi: 10.7575/aiac.ijalel.v.3n.4p.154. 